\title{
Cyclic electron flow and light partitioning between the two photosystems in leaves of plants with different functional types
}

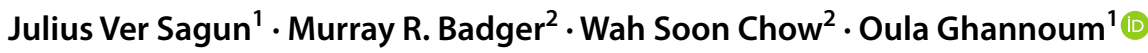

Received: 18 April 2019 / Accepted: 26 August 2019 / Published online: 13 September 2019

(c) The Author(s) 2019

\begin{abstract}
Cyclic electron flow (CEF) around photosystem I (PSI) is essential for generating additional ATP and enhancing efficient photosynthesis. Accurate estimation of CEF requires knowledge of the fractions of absorbed light by PSI $\left(f_{\mathrm{I}}\right)$ and PSII $\left(f_{\mathrm{II}}\right)$, which are only known for a few model species such as spinach. No measures of $f_{\mathrm{I}}$ are available for $\mathrm{C}_{4}$ grasses under different irradiances. We developed a new method to estimate (1) $f_{\mathrm{II}}$ in vivo by concurrently measuring linear electron flux through both photosystems $\left(\mathrm{LEF}_{\mathrm{O}_{2}}\right)$ in leaf using membrane inlet mass spectrometry (MIMS) and total electron flux through PSII (ETR2) using chlorophyll fluorescence by a Dual-PAM at low light and (2) CEF as ETR1- $\mathrm{LEF}_{\mathrm{O}_{2}}$. For a $\mathrm{C}_{3}$ grass, $f_{\mathrm{I}}$ was 0.5 and 0.4 under control (high light) and shade conditions, respectively. $\mathrm{C}_{4}$ species belonging to NADP-ME and NAD-ME subtypes had $f_{\mathrm{I}}$ of 0.6 and PCK subtype had 0.5 under control. All shade-grown $\mathrm{C}_{4}$ species had $f_{\mathrm{I}}$ of 0.6 except for NADP-ME grass which had 0.7. It was also observed that $f_{\mathrm{I}}$ ranged between 0.3 and 0.5 for gymnosperm, liverwort and fern species. $\mathrm{CEF}$ increased with irradiance and was induced at lower irradiances in $\mathrm{C}_{4}$ grasses and fern relative to other species. CEF was greater in shade-grown plants relative to control plants except for $\mathrm{C}_{4}$ NADP-ME species. Our study reveals a range of $\mathrm{CEF}$ and $f_{\mathrm{I}}$ values in different plant functional groups. This variation must be taken into account for improved photosynthetic calculations and modelling.
\end{abstract}

Keywords C4 photosynthesis · Chlorophyll fluorescence $\cdot$ Cyclic electron flux $\cdot$ Electron transport rate $\cdot$ Oxygen exchange rate $\cdot$ Photosystem

\section{Introduction}

Photosynthetic electron transport in the thylakoid membrane of chloroplasts is highly regulated to cope with fluctuating light intensity and variable demand for ATP and NADPH.

Electronic supplementary material The online version of this article (https://doi.org/10.1007/s11120-019-00666-1) contains supplementary material, which is available to authorized users.

Julius Ver Sagun

J.Sagun@westernsydney.edu.au

Oula Ghannoum

O.Ghannoum@westernsydney.edu.au

1 ARC Centre of Excellence for Translational Photosynthesis, Hawkesbury Institute for the Environment, Western Sydney University, Hawkesbury Campus, Locked Bag 1797, Penrith, NSW 2751, Australia

2 ARC Centre of Excellence for Translational Photosynthesis, Research School of Biology, Australian National University, Canberra, ACT 2601, Australia
Photon energy absorbed by pigments and the light-harvesting complexes drives electron transport through the thylakoid membranes. Electrons produced from the splitting of water molecule in photosystem II (PSII) are ultimately transferred via the cytochrome cyt $b_{6} / f$ complex and photosystem I (PSI) to $\mathrm{NADP}^{+}$, resulting in the production of reducing equivalents in the form of NADPH. These two processes, known as linear electron flow (LEF), generate a proton gradient across the thylakoid membrane $(\Delta \mathrm{pH})$. The $\Delta \mathrm{pH}$ together with a membrane potential formed across the thylakoid membrane $(\Delta \psi)$ drives the production of ATP via ATP synthase (Allen 2003).

During cyclic electron flow (CEF), NADPH or ferredoxin (Fd) is photoreduced at PSI and donates electrons to the cyt $b_{6} / f$ complex via the plastoquinone (PQ) pool. There, the Q-cycle transfers $1 \mathrm{H}^{+}$from the stroma to the lumen for each electron donated, resulting in a $\Delta \mathrm{pH}$, which can drive ATP synthesis without producing NADPH in chloroplasts (Allen 2003). This process is not only key to photo-protection, but also essential for increasing the ATP/NADPH 
ratio. Depending on the environmental and/or physiological conditions, this ratio can be adjusted to the required levels by tuning the ratio of LEF to CEF (Miyake 2010; Shikanai 2007; Takahashi and Badger 2011).

In angiosperms, CEF operates through two known pathways (Yamori and Shikanai 2016). The major pathway depends on two additional proteins, PROTONGRADIENT REGULATION 5 (PGR5) (Munekage et al. 2002) and PGR5-LIKE PHOTOSYNTHETIC PHENOTYPE 1 (PGRL1) (DalCorso et al. 2008), whereas the minor activity pathway is mediated by a chloroplast NADH dehydrogenaselike (NDH) complex (Burrows et al. 1998; Horváth et al. 2000; Shikanai et al. 1998). Antimycin A is an inhibitor of PGR5/PGRL1-dependent CEF, but the site of inhibition has long been unclear in chloroplasts (Munekage et al. 2002).

In the absence of PGR5/PGRL1-dependent pathway, the chloroplast NDH-dependent pathway compensates for the loss of the important pathway to some extent (Munekage et al. 2004; Shikanai 2014). The chloroplast NDH complex, which is insensitive to antimycin A, recycles electrons from ferredoxin to plastoquinone and subsequently to PSI through the cyt $b_{6} / f$ complex (Shikanai 2016). In contrast to higher plants, Godde (1982) showed that the green alga Chlamydomonas reinhardtii CW-15 was able to use NADH as electron donor for its photosynthetic electron flow. They also showed that NDH is sensitive to rotenone and thenoyltrifluoroacetone (TTFA). This finding is important because it was recently shown that the NDH system is the main pathway for CEF in Paniceae $\mathrm{C}_{3}$ and $\mathrm{C}_{4}$ grasses (HernándezPrieto et al. 2019).

A prerequisite to understanding the role of CEF is the ability to quantify CEF under physiological conditions, which has been difficult due to the absence of a net product of CEF (Shikanai 2014). Unlike LEF, the rate of CEF cannot be monitored by $\mathrm{O}_{2}$ evolution or reduction of artificial electron acceptors from PSI. Fan et al. (2016) grouped current methods for measuring and inferring CEF into two categories: (1) monitor CEF directly and (2) estimate CEF from the difference between LEF through PSII (ETR2) and total flux through PSI (ETR1). They concluded that CEF quantification in $\mathrm{C}_{3}$ leaves is best approximated through measurements of ETR1 and ETR2 under identical conditions according to category 2.

Measurement of the electron flux through PSI (ETR1) can be done via a Y(I)-based electron flux (Klughammer and Schreiber 2008). ETR1, based on Y(I), is then calculated as

$\mathrm{ETR} 1=\mathrm{Y}(\mathrm{I}) \times I \times 0.85 \times f_{\mathrm{I}}$

where $I$ is the irradiance, 0.85 is the assumed leaf absorptance and $f_{\mathrm{I}}$ is the fraction of the absorbed white light partitioned to PSI. It is worth noting that it is not easy to determine $f_{\mathrm{I}}$ experimentally under variable environmental conditions; yet, calculations of ETR1 and CEF rate depend on an accurate estimation of $f_{\mathrm{I}}$. This value can be experimentally determined under low irradiance and/or in the presence of CEF inhibitors such as antimycin A, where CEF is assumed to be zero; hence, ETR2 is supposed to be approximately equal to ETR $1\left(f_{\mathrm{I}}\right.$ values are in the range $\left.0.4-0.5\right)$ (Kou et al. 2013a, b). However, the validity of these methods needs further evaluation.

On the other hand, measurement of ETR2 on whole tissue can be better obtained by gross rate of $\mathrm{O}_{2}$ evolution recorded by a gas-phase oxygen electrode compared to chlorophyll fluorescence technique (Fan et al. 2016), if the latter is not optimised. Since four electrons are released for each $\mathrm{O}_{2}$ molecule evolved, ETR2 (now $\mathrm{LEF}_{\mathrm{O}_{2}}$ ) equals four times the gross rate of $\mathrm{O}_{2}$ evolution (Chow et al. 1989; Kou et al. 2013a, b). Membrane inlet mass spectrometry (MIMS), utilising the stable ${ }^{18} \mathrm{O}_{2}$ isotope to differentially and simultaneously measure rates of $\mathrm{O}_{2}$ uptake and evolution, provides a more precise method to accurately quantify ETR2 under near-natural conditions (Beckmann et al. 2009). It also allows the $\mathrm{CO}_{2}$ concentration to be monitored in the cuvette to ensure photorespiration does not significantly contribute to the $\mathrm{O}_{2}$ uptake signal.

The overall aim of our study was to determine to what extent CEF and $f_{\mathrm{I}}$ vary between $\mathrm{C}_{3}$ and $\mathrm{C}_{4}$ plants, and in response to variation in light intensity. $f_{\mathrm{I}}$ and $f_{\mathrm{II}}$ are only known for a few species, commonly $\mathrm{C}_{3}$, and $f_{\mathrm{I}}$ is always assumed to be 0.5 in untested species. It is also unknown in ferns, liverwort, gymnosperms or among the various $\mathrm{C}_{4}$ species. In particular, $\mathrm{C}_{4}$ photosynthesis possesses $\mathrm{CO}_{2}$-concentrating mechanisms $(\mathrm{CCM})$ which operates across two photosynthetic cell types (mesophyll and bundle sheath) and serves to supercharge photosynthesis and minimise photorespiration in air. $\mathrm{C}_{4}$ plants are broadly grouped into three biochemical subtypes according to the primary $\mathrm{C}_{4}$ acid decarboxylase (NADP-ME, NAD-ME and PCK) operating in the bundle sheath (Hatch 1987). Consequently, we developed a new method which can give a more reliable estimation of ETR2 based on (a) MIMS and (b) the chlorophyll fluorescence-derived Y(II) method using a Dual-PAM/F. This can concurrently measure Y(II) and $\mathrm{LEF}_{\mathrm{O}_{2}}$ in leaf discs in $\mathrm{CO}_{2}$-enriched air applied to leaf discs of $\mathrm{C}_{3}$ and $\mathrm{C}_{4}$ plants. Leaf discs from representative species of liverwort, fern and angiosperms were also measured. This method also allowed us to experimentally determine $f_{\mathrm{I}}$ and use it to calculate ETR 1 and CEF in chloroplasts of all species. Measurements were taken in the presence of CEF inhibitors (antimycin A and TTFA) and/ or in low irradiance where CEF is assumed to be zero. In addition, this study determined the effect of low-light (shade) condition on light partitioning between the two photosystems. 


\section{Materials and methods}

\section{Plant culture}

Representative grass species of $\mathrm{C}_{3}$ (Panicum bisulcatum), $\mathrm{C}_{4}$ NADP-ME subtype (Panicum antidotale), $\mathrm{C}_{4}$ NAD-ME subtype (Panicum miliaceum) and $\mathrm{C}_{4} \mathrm{PCK}$ subtype (Megathyrsus maximus) and Zea mays (model $\mathrm{C}_{4}$ NADP-ME species) were grown in vermiculite in a naturally lit greenhouse (control) made of polycarbonate at the Australian National University. The greenhouse temperature was maintained at $28 / 24{ }^{\circ} \mathrm{C}$ for day/night via an in-built greenhouse temperature control system. Within the greenhouse, a steel structure was placed and covered with shade cloth which was used for shade treatment. The average ambient photosynthetic photon flux densities (PPFD) and temperature during the mid-day were 800 and $300 \mu \mathrm{mol}$ photons $\mathrm{m}^{-2} \mathrm{~s}^{-1}$ and $30^{\circ} \mathrm{C}$ and $29^{\circ} \mathrm{C}$ for control and shade treatments, respectively. Leaves were harvested from 4- to 5-week-old plants. Representative species of gymnosperms (Ginkgo biloba and Wollemi nobilis), liverwort (Marchantia polymorpha) and fern (Polypodium sp.) and spinach (model $\mathrm{C}_{3}$ species) grown under full sunlight were also used. All plants were watered regularly and fertilised with Osmocote ${ }^{\circledR}$ (Scotts Australia).

\section{Membrane inlet mass spectrometry (MIMS)}

Gas exchange was measured in a closed cuvette coupled to a mass spectrometer as described by Maxwell et al. (1998) and Dual-PAM/F (Heinz Walz) (Fig. S 1). Leaf discs $\left(1.89 \mathrm{~cm}^{2}\right.$ area) were punched from the leaf and immediately placed within the chamber together with the wet filter paper supported on a mesh of equal area. The cuvette was first calibrated for oxygen and then flushed with nitrogen gas. Then, a known volume of $\mathrm{CO}_{2}$ was added to create an atmosphere of approximately $4 \% \mathrm{CO}_{2}$ (high $p \mathrm{CO}_{2}$ ) within the chamber; ${ }^{18} \mathrm{O}_{2}$ was injected to give an atmosphere of $18-21 \% \mathrm{O}_{2}$ and the signals were allowed to stabilise for $10 \mathrm{~min}$. Gas consumption and leakage from the cuvette were negligible. The leaf was then illuminated at increasing irradiance from 50 to $2000 \mu$ mol photons $\mathrm{m}^{-2} \mathrm{~s}^{-1}$. The chamber temperature was maintained at $28^{\circ} \mathrm{C}$.

\section{Measurement of ETR1}

Measurement of the electron flux through PSI (ETR1) was taken via a Y(I)-based electron flux in leaf discs at $28^{\circ} \mathrm{C}$ using the FIBER version of Dual-PAM (Dual-PAM/F) with a dual wavelength $(830 / 875 \mathrm{~nm})$ unit (Walz, Effeltrich, Germany) connected to the gas exchange system via a light guide to permit simultaneous measurements. The fibre optic cable was positioned within the Perspex lid at a distance of $1.0 \mathrm{~cm}$ from the leaf surface. The Perspex lid weakened the light intensity coming from Dual-PAM/F by $\sim 87 \%$, so we added external white actinic (AL, from a halogen lamp), strong far-red (sFR), weak far-red (wFR) and saturating light sources through various branches of the multifurcated light guide.

The photochemical yield of PSI, Y(I), in AL at a given irradiance was obtained by the percentage of the photo-oxidisable P700. The P700 redox state was measured following the method of Klughammer and Schreiber (1994). A saturation pulse (SP) $\left(\sim 10,000 \mu \mathrm{mol}\right.$ photons $\left.\mathrm{m}^{-2} \mathrm{~s}^{-1}\right)$, which was introduced primarily for PAM fluorescence measurement, was applied for assessment of P700 parameters. The P700 single channel in SP-analysis mode of the Dual-PAM software was used for this purpose.

The maximum photo-oxidisable P700 content $\left(P_{\mathrm{m}}\right)$ was first recorded as a prerequisite for the calculation of $\mathrm{Y}(\mathrm{I})$, non-photochemical quantum yield of PSI due to donor-side limitation $\mathrm{Y}(\mathrm{ND})$ and non-photochemical quantum yield of PSI due to acceptor side limitation Y(NA). This was done by first determining a steady state by illuminating the leaf disc with wFR $\left(\sim 50 \mu \mathrm{mol}\right.$ photons $\left.\mathrm{m}^{-2} \mathrm{~s}^{-1}, 723 \mathrm{~nm}\right)$ for $>10 \mathrm{~s}$ (Fig. S 2A) coming from an external light source which was manually controlled. This intensity of wFR light was strong enough to oxidise most of the P700 in the steady state but not strong enough to drive electrons in the intersystem chain. Then, a 200-ms SP $(\sim 10,000 \mu$ mol photons $\mathrm{m}^{-2} \mathrm{~s}^{-1}$ ) coming from Dual-PAM/F and external light source was superimposed to photo-oxidise the remainder of the P700 (Fig. S 2A). This additional external saturating light source was connected to the TRIGGER OUT socket of Dual$\mathrm{PAM} / \mathrm{F}$. Both pulses were triggered at the same time through the Dual-PAM software in "Trigger out" mode.

The leaf disc was light-adapted for at least 10 min with AL $\left(1000 \mu \mathrm{mol}\right.$ photons $\left.\mathrm{m}^{-2} \mathrm{~s}^{-1}\right)$ to reach steady-state photosynthesis before measurements of light response curves. Light-adapted photosynthetic parameters were recorded after 8- to 10-min exposure to each AL intensity $(50,100$, $200,300,400,500,750,1000,1500$ and $2000 \mu$ mol photons $\mathrm{m}^{-2} \mathrm{~s}^{-1}$ ) and when the rate of gross oxygen evolution was stable.

Fast kinetic recording in "External trigger" mode by the Dual-PAM was first started. The leaf disc was re-illuminated with the same AL for $10 \mathrm{~s}$ to retain a steady state for $\mathrm{P} 700^{+}$measurements immediately after the photosynthetic induction step using an electronic shutter controlled by one terminal of a pulse/delay generator (Model 555, Berkeley Nucleonics, San Rafael, CA, USA) connected to DualPAM/F. During each 10 -s illumination, at time $T=8.80 \mathrm{~s}$ (corresponding to the time point $200 \mathrm{~ms}$ in Fig. S 2B), data acquisition by the Dual-PAM was started by a trigger pulse from a second terminal of the pulse/delay generator. 
At $T=8.95 \mathrm{~s}$, a sFR $\left(\sim 4000 \mu \mathrm{mol}\right.$ photons $\left.\mathrm{m}^{-2} \mathrm{~s}^{-1}\right)$ from two external light-emitting diode arrays $(741 \mathrm{~nm} \pm 13 \mathrm{~nm}$, LED735-66-60, Roithner LaserTechnik, Vienna, Austria) was triggered on for $250 \mathrm{~ms}$ using a third terminal of the pulse/delay generator. The sFR depleted electrons from the inter-system chain, so that the subsequent saturating pulse oxidised P700 maximally (Siebke et al. 1997). While the sFR was on, at $T=9.0 \mathrm{~s}, \mathrm{SP}(\sim 10,000 \mu \mathrm{mol}$ photons $\mathrm{m}^{-2} \mathrm{~s}^{-1}$ ) was applied for $200 \mathrm{~ms}$ by a pulse from Dual-PAM/F and a fourth terminal of the pulse/delay generator, yielding the maximally oxidised $P_{\mathrm{m}}^{\prime}$ signal (where $P_{\mathrm{m}}^{\prime}$ is the maximum $\mathrm{P} 00^{+}$signal in AL) in Fig. $\mathrm{S} 2 \mathrm{~B}$. Finally, AL was turned off by the electronic shutter (at $T=9.016 \mathrm{~s}$ ). Data acquisition continued for $1200 \mathrm{~ms}$ after cessation of AL to obtain the baseline corresponding to complete re-reduction of $\mathrm{P} 700^{+}$. Y(I) was then calculated by the Dual-PAM from the complimentary PSI quantum yields of non-photochemical energy dissipation $\mathrm{Y}(\mathrm{ND})$ and $\mathrm{Y}(\mathrm{NA})$ :

$\mathrm{Y}(\mathrm{I})=1-\mathrm{Y}(\mathrm{ND})-\mathrm{Y}(\mathrm{NA})$

$\mathrm{Y}(\mathrm{ND})$ and $\mathrm{Y}(\mathrm{NA})$ were directly determined by the saturation pulse method. Y(ND) represents the fraction of overall P700 that is oxidised in a given state. It is calculated as:

$\mathrm{Y}(\mathrm{ND})=1-\mathrm{P} 700_{\text {red. }}$

where $\mathrm{P} 700_{\text {red }}$. is the fraction of $\mathrm{P} 700$ in the reduced state. As determination of $\mathrm{P} 700_{\text {red }}$. by the saturation pulse method requires previous $P_{\mathrm{m}}$ determination, the same also holds for Y(ND) determination. Y(NA), on the other hand, represents the fraction of overall P700 that cannot be oxidised by a saturation pulse in a given state due to lack of available acceptors. It is calculated as:

$\mathrm{Y}(\mathrm{NA})=\frac{\left(P_{\mathrm{m}}-P_{\mathrm{m}}^{\prime}\right)}{P_{\mathrm{m}}}$

ETR1 was then calculated as:

$\mathrm{ETR} 1=\mathrm{Y}(\mathrm{I}) \times I \times 0.85 \times f_{\mathrm{I}}$

where $I$ is the irradiance, 0.85 is the assumed absorptance and $f_{\mathrm{I}}$ is the assumed fraction of absorbed white light partitioned to PSI.

\section{Determination of $f_{1}$ and calculation of CEF}

Two techniques were compared in this study to determine $f_{\mathrm{I}}$ : (1) the use of CEF inhibitors and (2) simultaneous measurement of linear electron flux $\left(\mathrm{LEF}_{\mathrm{O}_{2}}\right)$ by $\mathrm{Chl}$ fluorescence and gross oxygen evolution rate under white actinic light of very low irradiances. In the first technique, CEF is assumed to be zero; thus, ETR2 is supposed to be approximately equal to ETR1. In the second technique, linear electron fluxes measured by $\mathrm{Chl}$ fluorescence and oxygen evolution are assumed to be equal.

To obtain $f_{\mathrm{I}}$ using the first technique, $f_{\mathrm{I}}$ was determined by inhibiting CEF with the use of antimycin A and TTFA. The cut end of the leaf was dipped into $200 \mu \mathrm{M}$ antimycin $\mathrm{A} / 200 \mu \mathrm{M}$ TTFA/ $\mathrm{H}_{2} \mathrm{O}$ solution (with a trace of ethanol) and allowed to absorb the solution in darkness overnight before measurement. Inhibitor concentration taken up by the leaf was calculated as:

Inhibitor concentration $=\frac{(\text { Volume of consumed solution } 200 \mu \mathrm{M})}{(\text { Leaf fresh weight } \times 0.9)}$

where 0.9 represents the $90 \%$ water content of the leaf. Discs were collected and used for Y(I)-based measurement of ETR1 after absorbing $\geq 200 \mu \mathrm{M}$ of each inhibitor. Assuming that:

$\mathrm{ETR} 1=\mathrm{LEF}_{\mathrm{O}_{2}}$

then

$\mathrm{LEF}_{\mathrm{O}_{2}}=\mathrm{Y}(\mathrm{I}) \times I \times 0.85 \times f_{I}$

$f_{I}$ was then calculated as:

$f_{\mathrm{I}}=\frac{\mathrm{LEF}_{\mathrm{O}_{2}}}{\mathrm{Y}(\mathrm{I}) \times I \times 0.85}$

CEF in leaf in the absence of inhibitors was then calculated as:

$\mathrm{CEF}=\mathrm{ETR} 1-\mathrm{LEF}_{\mathrm{O}_{2}}$

To obtain $f_{\mathrm{I}}$ using the second technique, the fraction of absorbed white light partitioned to PSII, $f_{\text {II }}$, was first estimated in leaf discs of different species by measuring the photochemical yield of PS II, Y(II), by Chl fluorescence and the gross oxygen evolution rate simultaneously at low irradiance $\left(50,100,200,300 \mu \mathrm{mol}\right.$ photons $\left.\mathrm{m}^{-2} \mathrm{~s}^{-1}\right)$ and high $p \mathrm{CO}_{2}(4 \%)$. Chl fluorescence was measured with the fluorescence single channel in SP-analysis mode of the Dual-PAM software when the gas exchange signals were all stable. The steady-state fluorescence yield $\left(F_{\mathrm{s}}\right)$ was first monitored continuously under low irradiances, and a 300-ms pulse of saturating light $\left(\sim 10,000 \mu \mathrm{mol}\right.$ photons $\left.\mathrm{m}^{-2} \mathrm{~s}^{-1}\right)$ was supplied to determine maximum variable fluorescence $\left(F_{\mathrm{m}}^{\prime}\right)$. Y(II) at the steady state was defined as $\left(F_{\mathrm{m}}^{\prime}-F_{\mathrm{s}}\right) / F_{\mathrm{m}}^{\prime}$, as proposed by Genty et al. (1989). ETR2 was then calculated as:

$\mathrm{ETR} 2=\mathrm{Y}(\mathrm{II}) \times I \times 0.85 \times f_{\mathrm{II}}$

Under low actinic irradiance $(<500 \mu \mathrm{mol}$ photons $\mathrm{m}^{-2} \mathrm{~s}^{-1}$ ), Kou et al. (2013a) showed that ETR2 can be equated to $\mathrm{LEF}_{\mathrm{O}_{2}}$; further, at low actinic irradiance, the matching of ETR2 with $\mathrm{LEF}_{\mathrm{O}_{2}}$ is independent of the spectral distribution of the excitation light (Zhang et al. 2018). $\mathrm{LEF}_{\mathrm{O}_{2}}$ in the present study is the gross oxygen evolution rate 
during illumination recorded by MIMS multiplied by four (since four electrons are released for each oxygen molecule evolved). Assuming that:

$\mathrm{ETR} 2=\mathrm{LEF}_{\mathrm{O}_{2}}$

then

$\mathrm{LEF}_{\mathrm{O}_{2}}=\mathrm{Y}(\mathrm{II}) \times I \times 0.85 \times f_{\text {II }}$

allowing $f_{\text {II }}$ to be evaluated. $f_{\mathrm{I}}$ was then calculated as:

$f_{\mathrm{I}}=1-f_{\mathrm{II}}$

The ETR 2 obtained by the gross oxygen evolution rate is based on whole-tissue measurement and can be validly compared with ETR1 obtained from Y(I). This is because the $\mathrm{P} 700^{+}$signal is also a whole-tissue measurement, by virtue of the fact that the measuring beams at 820 and $870 \mathrm{~nm}$ are only weakly absorbed by the leaf tissue and are, therefore, multiply scattered in the tissue until they are finally absorbed; subtraction of $\mathrm{LEF}_{\mathrm{O}_{2}}$ from ETR1 is then valid, as both refer to the same leaf tissue (Fan et al. 2016).

\section{Data analysis}

For each variable, four replicates (independent samples) were obtained for the two light treatments. The results were subjected to analysis of variance, and the means were compared by the Tukey test at $5 \%$ probability.

\section{Results}

\section{Comparing two methods for estimating the fraction of absorbed light partitioned to PSI $\left(f_{1}\right)$}

Estimation of CEF from ETR1 requires prior information on $f_{\mathrm{I}}$, which, in turn, requires a situation where CEF is small or negligible. This can be achieved by: (1) using inhibitors of CEF such as antimycin A and TTFA or (2) using low irradiance to drive LEF to produce minimal CEF. The efficiency of these two methods was evaluated by concurrently measuring fluorescence and P700 signals with mass spectrometric measurements of gross $\mathrm{O}_{2}$ evolution in a closed leaf chamber (Figs. S 1 and S 2).

Using the first method, leaf discs of $\mathrm{C}_{4}$ grasses $P$. miliaceum and M. maximus were infiltrated with $\sim 200 \mu \mathrm{M}$ solution of each inhibitor and $\mathrm{Y}(\mathrm{I})$ was measured using Dual-PAM/F under increasing irradiance from 100 to $2000 \mu \mathrm{mol}$ photons $\mathrm{m}^{-2} \mathrm{~s}^{-1}$. Assuming that CEF was completely inhibited, ETR 1 would approximately equal $\mathrm{LEF}_{\mathrm{O}_{2}}$ as in Eq. (6). Then, $f_{\mathrm{I}}$ can be estimated by equating ETR1 with $\mathrm{LEF}_{\mathrm{O}_{2}}$ and using measured $\mathrm{Y}(\mathrm{I})$ as in Eqs. (7) and (8). If CEF was inhibited in this method, $f_{\mathrm{I}}$ would be independent of irradiance (Kou et al. 2013a, b). However,
$f_{\mathrm{I}}$ decreased with increasing irradiance in all inhibitortreated leaf discs (Table $\mathrm{S}$ 1). In addition, $\mathrm{LEF}_{\mathrm{O}_{2}}$ of treated leaf discs was lower compared to untreated discs, probably due to the unknown, non-specific effect of inhibitors in photosynthetic electron transport. This could affect ETR1 calculation and underestimate $f_{\mathrm{I}}$ due to the side effects of high concentration of CEF inhibitors on photosynthesis. Consequently, we considered that this method was unreliable for $f_{\mathrm{I}}$ estimation.

The second method used Y(II) obtained by simultaneously measuring chl fluorescence and gross $\mathrm{O}_{2}$ evolution rate at low irradiance and high $p \mathrm{CO}_{2}$. This method is considered to be non-destructive in comparison with the use of CEF inhibitors (Table S 1). Since MIMS was directly connected to a Dual-PAM, simultaneous measurements of $\mathrm{O}_{2}$ evolution and the quantum yield of the photochemical reaction at PSII or PSI were possible which made us easily calculate light partitioning and various electron fluxes in leaf (Fig. 1a-d). The method is also mechanistic and quantitative which assumes a linear relationship between the gas exchange and photochemical yields which was adopted in a number of studies (Beckmann et al. 2009; Fan et al. 2016; Kono et al. 2014; Kou et al. 2013b, 2015; Laisk et al. 2014; Laisk and Loreto 1996; Loreto et al. 2009; Miyake and Yokota 2000; Miyake et al. 2004, 2005). At $\leq 300-500 \mu \mathrm{mol}$ photons $\mathrm{m}^{-2} \mathrm{~s}^{-1}$, CEF was assumed to be negligible in $\mathrm{CO}_{2}$-enriched air. Under these conditions, Kou et al. (2013a) showed that ETR2 roughly matched $\mathrm{LEF}_{\mathrm{O}_{2}}$ in spinach. We equated $\mathrm{LEF}_{\mathrm{O}_{2}}$ to ETR2 as in Eq. (11). Then, using Y(II) obtained from Dual-PAM/F, $f_{\text {II }}$ was obtained according to Eq. (12) and subtracted from 1 to give $f_{\mathrm{I}}$. The estimated $f_{\mathrm{II}}$ derived from Y(II) measurement was used to calculate a new ETR2 and plotted against irradiance, as was $\mathrm{LEF}_{\mathrm{O}_{2}}$. Results showed that ETR2 of control and shade-grown Z. mays (NADP-ME) (Fig. 1a and c) and P. bisulcatum $\left(\mathrm{C}_{3}\right.$ grass) (Fig. $1 \mathrm{~b}$ and d) roughly matched $\mathrm{LEF}_{\mathrm{O}_{2}}$ at irradiance $<300-500 \mu \mathrm{mol}$ photons $\mathrm{m}^{-2} \mathrm{~s}^{-1}$. Hence, this method was considered more reliable compared to the first at low irradiance and was subsequently used for $f_{\mathrm{I}}$ estimation of other species.

Utilising our second more reliable method, we calculated $f_{I}$ for the species used in this study (Table 1). All control $\mathrm{C}_{4}$ species had estimated $f_{\mathrm{I}}$ of 0.6 except for PCK grass $(M$. maximus) which had 0.5 . On the other hand, $f_{\mathrm{I}}$ of shadegrown $\mathrm{C}_{4}$ species remained constant except for NADP-ME grass ( $P$. antidotale) which had 0.7 (Table 1). Control $\mathrm{C}_{3}$ grass (P. bisulcatum) had $f_{\mathrm{I}}$ of 0.4 which is lower compared to spinach $\left(\mathrm{C}_{3}\right.$ model species), having $f_{\mathrm{I}}$ of 0.5 (Table 1$)$. However, shade-grown $\mathrm{C}_{3}$ grass had $f_{\mathrm{I}}$ of 0.5 . Other species such as liverwort (M. polymorpha) and fern (Polypodium sp.) had $f_{\mathrm{I}}$ of 0.5 , while the two species of gymnosperms had lower $f_{\mathrm{I}}$ which was 0.4 for $G$. biloba and 0.3 for W. nobilis (Table 1). Overall, there was a significant species $\times$ treatment effect on both $f_{\mathrm{I}}$ and $f_{\text {II }}$ (Table 2). 
Fig. 1 Electron fluxes through PSII in response to measurement irradiance calculated in two different ways in leaf discs of control (a) and shade-grown (c) Zea mays (NADP-ME) and control (b) and shade-grown (d) Panicum bisulcatum $\left(\mathrm{C}_{3}\right.$ grass). $\mathrm{LEF}_{\mathrm{O}_{2}}$ (the gross oxygen evolution rate multiplied by four) represents the linear electron flux through both photosystems; ETR2 is the measure of electron flux through PSII based on Chl fluorescence emitted from a certain depth in leaf tissue calculated using experimentally derived $f_{\text {III }}$. Measurements were taken under the temperature of $28{ }^{\circ} \mathrm{C}$ and high $p \mathrm{CO}_{2}$ condition $(4 \%)$. Values are mean \pm S.E. $(n=4$ leaf discs $)$

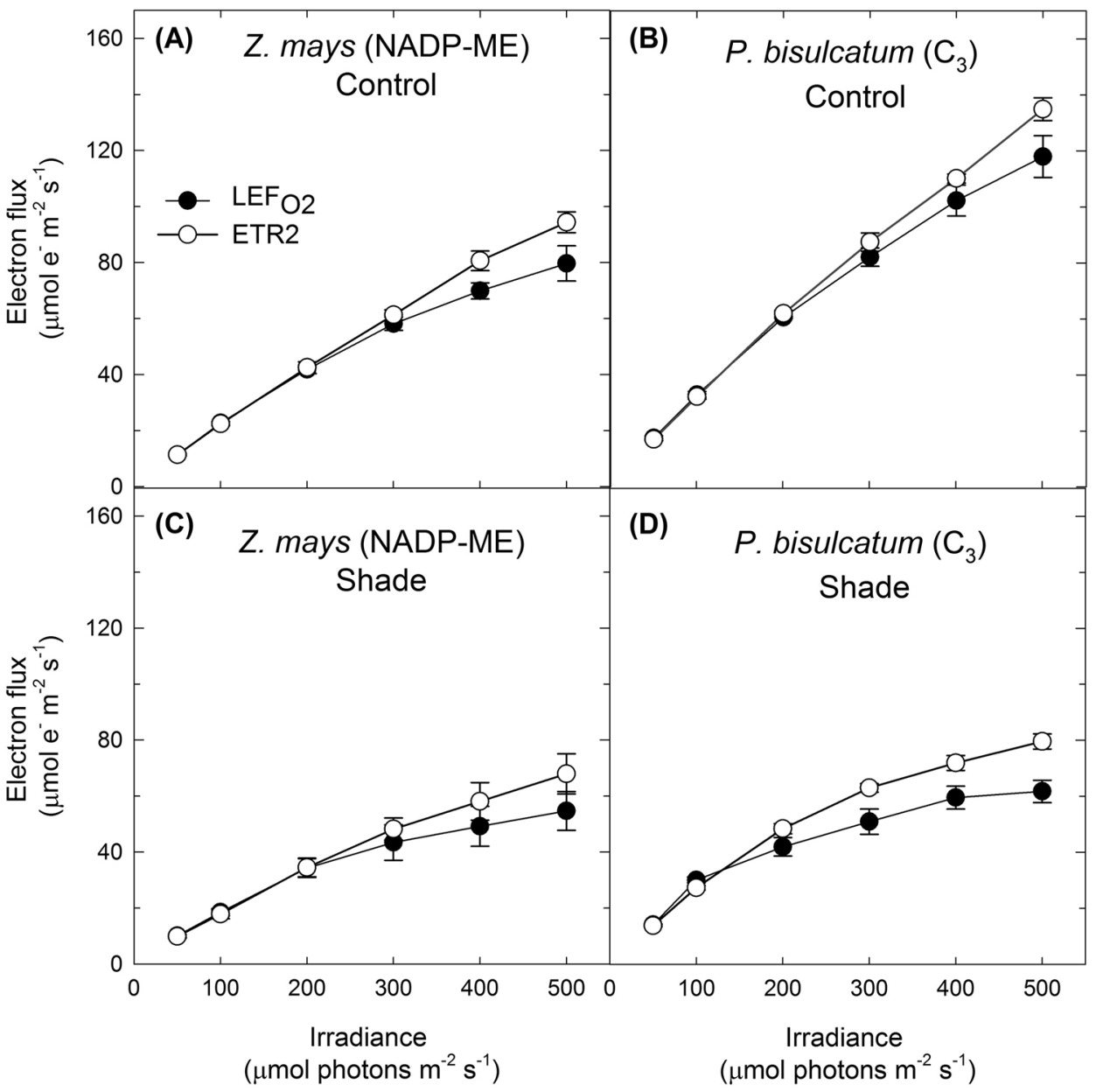

\section{The response of ETR1 and CEF in $C_{3}$ and $C_{4}$ grass species to shade}

Using our estimated $f_{\mathrm{I}}$ values to calculate ETR1, it was observed that ETR1 was higher in control NADP-ME (Fig. 2b) and NAD-ME (Fig. 2c) grasses by $\sim 20 \%$ and lower in control PCK ( 9\%) (Fig. 2d) and $\mathrm{C}_{3}(\sim 16 \%)$ (Fig. 2a) grasses when compared to uncorrected ETR1 (calculated using $f_{\mathrm{I}}=0.5$ ). Using corrected ETR 1 , CEF was then calculated using Eq. (9). At $\geq 500 \mu \mathrm{mol}$ photons $\mathrm{m}^{-2} \mathrm{~s}^{-1}$, CEF increased by $\sim 32 \%$ and $38 \%$ in control NADP-ME (Fig. 2b) and NAD-ME (Fig. 2c) grasses and decreased by $\sim 14 \%$ and $\sim 28 \%$ in control PCK (Fig. 2d) and $\mathrm{C}_{3}$ (Fig. 2a) grasses, respectively. Overall, there was no significant species $\mathrm{x}$ treatment effect on ETR1, CEF and $\mathrm{LEF}_{\mathrm{O}}$ measured at saturating irradiance $\left(2000 \mu \mathrm{mol}\right.$ photons $\left.\mathrm{m}^{-2} \mathrm{~s}^{-1}\right)$ (Table 2). However, when measured at low, medium and saturating irradiance $\left(200,1000\right.$ and $2000 \mu$ mol photons $\left.\mathrm{m}^{-2} \mathrm{~s}^{-1}\right)$, leaf discs of all shade-grown grass species had significantly higher CEF rates compared to the control counterparts (Fig. 3a-d), except for the NADP-ME grass which had no significant difference to the control (Fig. 3b).
When measured at low irradiance, CEF rates increased the most in shade-grown $\mathrm{C}_{3}$ grass $(+1900 \%)$ (Fig. 3a) followed by PCK grass $(+1395 \%)$ (Fig. 3D), NADPME grass $(+86 \%)$ (Fig. 3 b) and NAD-ME grass $(+75 \%)$ (Fig. 3c) relative to the control counterparts. Highest increase in $\mathrm{CEF}$ rate measured at saturating irradiance was again observed in shade-grown $\mathrm{C}_{3}$ grass $(+58 \%$ ) (Fig. 3a) followed by PCK grass (+32\%) (Fig. 3d), NAD-ME grass $(+29 \%)$ (Fig. 3c) and NADP-ME grass (+3\%) (Fig. 3b) species relative to the control counterparts.

Among shade-grown plants, CEF rates measured at medium irradiance $\left(1000 \mu \mathrm{mol}\right.$ photons $\left.\mathrm{m}^{-2} \mathrm{~s}^{-1}\right)$ were $\sim 35 \%$ higher in P. miliaceum (NAD-ME), M. maximus (PCK) and Z. mays (NADP-ME) relative to $P$. bisulcatum $\left(\mathrm{C}_{3}\right)$ and $P$. antidotale (NADP-ME) (Tables 2 and $\mathrm{S} 2$ ).

It was also observed that $\mathrm{LEF}_{\mathrm{O}_{2}}$ was significantly lower in all shade-grown species relative to the control counterparts when measured at medium irradiance (Tables 2 and S 2). However, ETR1 was not affected by the shade treatment in any of the species except for $P$. antidotale, where ETR 1 decreased by $28 \%$ under shade (Tables 2 and S 2). 
Table 1 An estimation of the fraction of absorbed light partitioned to PSI $\left(f_{\mathrm{I}}\right)$ obtained by $\mathrm{Chl}$ fluorescence method measured under low irradiances, high $p \mathrm{CO}_{2}$ conditions $(4 \%)$ and temperature of $28{ }^{\circ} \mathrm{C}$ in leaf of control and shade-grown $\mathrm{C}_{3}, \mathrm{C}_{4}$, gymnosperm, fern and liverwort species

\begin{tabular}{|c|c|c|}
\hline Irradiance $\left(\mu \mathrm{mol}\right.$ photons $\mathrm{m}^{-2} \mathrm{~s}^{-1}$ ) & $f_{\mathrm{I}}$ control & $f_{\mathrm{I}}$ shade \\
\hline \multicolumn{3}{|l|}{ Panicum bisulcatum $(n=4)\left(C_{3}\right)$} \\
\hline 50 & $0.40 \pm 0.02$ & $0.51 \pm 0.01$ \\
\hline 100 & $0.40 \pm 0.01$ & $0.47 \pm 0.02$ \\
\hline 200 & $0.43 \pm 0.01$ & $0.59 \pm 0.02$ \\
\hline 300 & $0.45 \pm 0.02$ & $0.61 \pm 0.03$ \\
\hline \multicolumn{3}{|c|}{ Panicum miliaceum $(n=4)(\mathrm{NAD}-\mathrm{ME})$} \\
\hline 50 & $0.60 \pm 0.01$ & $0.58 \pm 0.02$ \\
\hline 100 & $0.58 \pm 0.01$ & $0.59 \pm 0.01$ \\
\hline 200 & $0.62 \pm 0.02$ & $0.64 \pm 0.02$ \\
\hline 300 & $0.67 \pm 0.03$ & $0.69 \pm 0.02$ \\
\hline \multicolumn{3}{|l|}{ Megathyrsus maximus $(n=4)(\mathrm{PCK})$} \\
\hline 50 & $0.43 \pm 0.01$ & $0.54 \pm 0.03$ \\
\hline 100 & $0.42 \pm 0.00$ & $0.56 \pm 0.02$ \\
\hline 200 & $0.47 \pm 0.01$ & $0.63 \pm 0.03$ \\
\hline 300 & $0.50 \pm 0.01$ & $0.68 \pm 0.03$ \\
\hline \multicolumn{3}{|c|}{ Panicum antidotale $(n=4)$ (NADP-ME) } \\
\hline 50 & $0.60 \pm 0.02$ & $0.62 \pm 0.02$ \\
\hline 100 & $0.57 \pm 0.02$ & $0.65 \pm 0.01$ \\
\hline 200 & $0.57 \pm 0.02$ & $0.68 \pm 0.02$ \\
\hline 300 & $0.62 \pm 0.01$ & $0.73 \pm 0.02$ \\
\hline \multicolumn{3}{|l|}{ Zea mays $(n=8)$ (NADP-ME) } \\
\hline 50 & $0.58 \pm 0.02$ & $0.60 \pm 0.01$ \\
\hline 100 & $0.57 \pm 0.02$ & $0.59 \pm 0.02$ \\
\hline 200 & $0.58 \pm 0.02$ & $0.61 \pm 0.03$ \\
\hline 300 & $0.60 \pm 0.02$ & $0.65 \pm 0.03$ \\
\hline \multicolumn{3}{|l|}{ Spinach $(n=5)\left(\mathrm{C}_{3}\right)$} \\
\hline 50 & $0.49 \pm 0.01$ & \\
\hline 100 & $0.51 \pm 0.00$ & \\
\hline 200 & $0.50 \pm 0.00$ & \\
\hline 300 & $0.50 \pm 0.00$ & \\
\hline \multicolumn{3}{|l|}{ Ginkgo biloba $(n=4)$ (gymnosperm) } \\
\hline 50 & $0.37 \pm 0.01$ & \\
\hline 100 & $0.38 \pm 0.01$ & \\
\hline 200 & $0.43 \pm 0.00$ & \\
\hline 300 & $0.46 \pm 0.01$ & \\
\hline \multicolumn{3}{|l|}{ Wollemi nobilis $(n=4)$ (gymnosperm) } \\
\hline 50 & $0.22 \pm 0.03$ & \\
\hline 100 & $0.31 \pm 0.04$ & \\
\hline 200 & $0.49 \pm 0.07$ & \\
\hline 300 & $0.49 \pm 0.08$ & \\
\hline \multicolumn{3}{|l|}{ Polypodium sp. $(n=4)$ (fern) } \\
\hline 50 & $0.48 \pm 0.01$ & \\
\hline 100 & $0.54 \pm 0.01$ & \\
\hline 200 & $0.61 \pm 0.02$ & \\
\hline 300 & $0.59 \pm 0.01$ & \\
\hline
\end{tabular}

Table 1 (continued)

\begin{tabular}{|c|c|}
\hline Irradiance $\left(\mu \mathrm{mol}\right.$ photons $\left.\mathrm{m}^{-2} \mathrm{~s}^{-1}\right)$ & $f_{\mathrm{I}}$ control \\
\hline \multicolumn{2}{|c|}{ Marchantia polymorpha $(n=4)$ (liverwort) } \\
\hline 50 & $0.44 \pm 0.01$ \\
\hline 100 & $0.49 \pm 0.02$ \\
\hline 200 & $0.57 \pm 0.03$ \\
\hline 300 & $0.61 \pm 0.04$ \\
\hline
\end{tabular}

Values are mean \pm S.E.

\section{Rates of CEF of other species in response to irradiance}

$\mathrm{LEF}_{\mathrm{O}_{2}}$, ETR1 and CEF rates of all control species increased approximately linearly with irradiance (Tables 2 and $S$ 2). Operation of CEF at low irradiance $(200 \mu \mathrm{mol}$ photons $\mathrm{m}^{-2} \mathrm{~s}^{-1}$ ) was almost negligible in control $\mathrm{C}_{3}$ grass and gymnosperm species (Tables 2 and $\mathrm{S} 2$ ). This is because of the rate of $\mathrm{LEF}_{\mathrm{O}_{2}}$ almost equalled ETR1 (Table S 2), suggesting that all electrons from PSII were transferred to acceptors in PSI in these species without cycling around PSI. CEF started to operate between 400 and $750 \mu \mathrm{mol}$ photons $\mathrm{m}^{-2} \mathrm{~s}^{-1}$ in $\mathrm{C}_{3}$ grass and gymnosperm species, while operation of CEF in other species started at much lower irradiances (Table S 2). Among all control $\mathrm{C}_{4}$ species, rapid stimulation of CEF under low irradiance $\left(<400 \mu \mathrm{mol}\right.$ photons $\left.\mathrm{m}^{-2} \mathrm{~s}^{-1}\right)$ was observed in NADP-ME and NAD-ME species, while CEF of PCK grass was stimulated at much higher irradiance (Table $S$ 2 ). Among all species grown under high light, all grass species including $Z$. mays had higher $\mathrm{LEF}_{\mathrm{O}_{2}}$ compared to the gymnosperms, liverwort and fern when measured at medium irradiance (Fig. 4b; Tables 2 and S 2). NADP$\mathrm{ME}$ and NAD-ME grasses had the highest rates of CEF, which was not significantly different among the other species (Fig. 4b; Tables 2 and S 2). All shade-grown plants measured at low irradiance had lower rates of CEF and $\mathrm{LEF}_{\mathrm{O}_{2}}$ compared to the control counterparts measured at medium irradiance (Fig. 4a, b; Tables 2 and S 2). This suggests that electron fluxes of shade-grown plants operate at a slower rate under their growing light conditions in comparison with control plants. The ratio of CEF to $\mathrm{LEF}_{\mathrm{O}_{2}}$ was generally higher in $\mathrm{C}_{4}$ relative to $\mathrm{C}_{3}$ grass under both control and shade conditions (Fig. 4c). In addition, the $\mathrm{CEF}$ to $\mathrm{LEF}_{\mathrm{O}_{2}}$ ratio was not significantly different among the $\mathrm{C}_{4}$ grasses under either control or shade conditions (Fig. 4c). Liverwort and fern species had higher CEF to $\mathrm{LEF}_{\mathrm{O}_{2}}$ ratio relative to all other species under grown under high light (Fig. 4c). Overall, no significant species $\times$ treatment effect on CEF to $\mathrm{LEF}_{\mathrm{O}_{2}}$ ratio under low, medium and saturating light (Table 2). 
Table 2 Summary of statistical analysis using two-way ANOVA for the effects of shade and species on various parameters collected for nine plants grown under natural light $(\sim 800 \mu \mathrm{mol}$ photons $\left.\mathrm{m}^{-2} \mathrm{~s}^{-1}\right)$ and shaded $\left(\sim 300 \mu \mathrm{mol}\right.$ photons $\left.\mathrm{m}^{-2} \mathrm{~s}^{-1}\right)$ conditions

\begin{tabular}{|c|c|c|c|}
\hline \multirow[t]{2}{*}{ Parameter } & \multicolumn{2}{|c|}{ Main effects $(\mathrm{P})$} & \multirow{2}{*}{$\begin{array}{l}\text { Interactions }(\mathrm{P}) \\
\text { Species } \times \text { treatment }\end{array}$} \\
\hline & Species & Treatment & \\
\hline $\mathrm{Y}(\mathrm{II})$ & 0.021 & 0.000 & 0.014 \\
\hline $\mathrm{Y}(\mathrm{I})$ at low light & 0.001 & 0.080 & 0.240 \\
\hline Y(I) at medium light & 0.023 & 0.216 & 0.180 \\
\hline $\mathrm{Y}(\mathrm{I})$ at saturating light & 0.084 & 0.704 & 0.184 \\
\hline$f_{\mathrm{I}}$ & 0.000 & 0.000 & 0.003 \\
\hline$f_{\text {II }}$ & 0.000 & 0.000 & 0.003 \\
\hline $\mathrm{LEF}_{\mathrm{O}_{2}}$ at low light $\left(\mu \mathrm{mol} \mathrm{m} \mathrm{m}^{-2} \mathrm{~s}^{-1}\right)$ & 0.000 & 0.000 & 0.098 \\
\hline $\mathrm{LEF}_{\mathrm{O}_{2}}$ at medium light $\left(\mu \mathrm{mol} \mathrm{m} \mathrm{m}^{-2} \mathrm{~s}^{-1}\right)$ & 0.000 & 0.000 & 0.014 \\
\hline $\mathrm{LEF}_{\mathrm{O}_{2}}$ at saturating light $\left(\mu \mathrm{mol} \mathrm{m} \mathrm{m}^{-2} \mathrm{~s}^{-1}\right)$ & 0.000 & 0.000 & 0.140 \\
\hline ETR1 at low light $\left(\mu \mathrm{mol} \mathrm{m}{ }^{-2} \mathrm{~s}^{-1}\right)$ & 0.000 & 0.002 & 0.011 \\
\hline ETR1 at medium light $\left(\mu \mathrm{mol} \mathrm{m} \mathrm{m}^{-2} \mathrm{~s}^{-1}\right)$ & 0.000 & 0.779 & 0.039 \\
\hline ETR1 at saturating light $\left(\mu \mathrm{mol} \mathrm{m} \mathrm{m}^{-2} \mathrm{~s}^{-1}\right)$ & 0.000 & 0.210 & 0.122 \\
\hline CEF at low light $\left(\mu \mathrm{mol} \mathrm{m}{ }^{-2} \mathrm{~s}^{-1}\right)$ & 0.000 & 0.000 & 0.000 \\
\hline CEF at medium light $\left(\mu \mathrm{mol} \mathrm{m} \mathrm{m}^{-2} \mathrm{~s}^{-1}\right)$ & 0.000 & 0.000 & 0.266 \\
\hline $\mathrm{CEF}$ at saturating light $\left(\mu \mathrm{mol} \mathrm{m} \mathrm{m}^{-2} \mathrm{~s}^{-1}\right)$ & 0.000 & 0.000 & 0.341 \\
\hline $\mathrm{CEF} / \mathrm{LEF}_{\mathrm{O}_{2}}$ at low light & 0.000 & 0.000 & 0.544 \\
\hline $\mathrm{CEF} / \mathrm{LEF}_{\mathrm{O}_{2}}$ at medium light & 0.000 & 0.000 & 0.052 \\
\hline $\mathrm{CEF} / \mathrm{LEF}_{\mathrm{O}_{2}}$ at saturating light & 0.001 & 0.000 & 0.294 \\
\hline
\end{tabular}

Measurements were taken at low light $\left(200 \mu \mathrm{mol}\right.$ photons $\left.\mathrm{m}^{-2} \mathrm{~s}^{-1}\right)$, medium light $(1000 \mu \mathrm{mol}$ photons $\left.\mathrm{m}^{-2} \mathrm{~s}^{-1}\right)$ and saturating light $\left(2000 \mu \mathrm{mol}\right.$ photons $\left.\mathrm{m}^{-2} \mathrm{~s}^{-1}\right)$ under the temperature of $28{ }^{\circ} \mathrm{C}$ and high $p \mathrm{CO}_{2}$ condition $(4 \%)$

\section{Discussion}

In this study, we tested two methods to calculate the light partitioning between PSI and PSII ( $f_{\mathrm{I}}$ and $f_{\mathrm{II}}$, respectively) in several plant species by combining P700 measurement using a Dual-PAM and LEF measurement using MIMS. Given that our species of interest are not widely studied, we included spinach $\left(\mathrm{C}_{3}\right.$ model species $)$ and maize $\left(\mathrm{C}_{4}\right.$ model species $)$ in our study to compare our values with the literature. One method was more reliable and we adopted it to determine CEF around PSI.

\section{The use of CEF inhibitors is unreliable for $f_{I}$ estimation in leaves of $C_{4}$ grasses}

The concentration of the CEF inhibitors that should infiltrate the leaf must be $\geq 200 \mu \mathrm{M}$. At this concentration, Kou et al. (2013a) observed that antimycin A had no effect on $\mathrm{LEF}_{\mathrm{O}_{2}}$ assayed by $\mathrm{O}_{2}$ evolution and largely abolished CEF in spinach leaf discs. However, the same was not observed in some $\mathrm{C}_{4}$ grass leaves examined. After allowing the leaf to take up the inhibitor solution overnight, the leaf started to dry out and $\mathrm{LEF}_{\mathrm{O}_{2}}$ values were lower compared to the untreated leaf (Table $\mathrm{S}$ 1), possibly due to the unknown, non-specific effect of the inhibitors in many mechanisms of light reactions in the chloroplasts. The combination of these two potent CEF inhibitors might have multiple effects on photosynthesis. An example is from the study of Horton et al. (1991) where they found that antimycin A prevents LHCII aggregation which inhibits the process of excess excitation energy dissipation as heat $(\mathrm{qE})$. It was also observed that TTFA can inhibit photosynthetic electron transport in and around PSII complex in spinach as measured from chlorophyll fluorescence parameters (Ikezawa et al. 2002).

Aside from these reasons, it was also decided not to measure $f_{\mathrm{I}}$ under high irradiance for $\mathrm{C}_{4}$ plants because of the amount of charge recombination occurring in both mesophyll and bundle sheath chloroplasts (Takahashi et al. 2013; Kou et al. 2015). This direct charge recombination can keep P700 more reduced even CEF was inhibited. In this case, $\mathrm{Y}(\mathrm{I})$ would be greater than in the absence of direct charge recombination and smaller $f_{\mathrm{I}}$ values under increasing irradiance (Table S 1). This phenomenon was also observed in low-light-grown Arabidopsis that lacks NDH which still exhibited a substantial $\Delta$ Flux at high irradiance even in the presence of antimycin A, attributable to charge recombination in PSI and/or the Mehler reaction (Kou et al. 2015). Another possibility for $\mathrm{P} 700$ reduction is the reduction of stromal donors by ascorbate and malate under aerobic conditions with weak far-red light. It was shown by Ivanov et al. (2005) that addition of these metabolites strongly stimulated the development of a proton gradient in thylakoids of maize under aerobic conditions in the absence of DCMU, 
Fig. 2 Various electron fluxes in response to irradiance in leaf discs of control a Panicum bisulcatum $\left(\mathrm{C}_{3}\right.$ grass); $\mathbf{b}$ Panicum antidotale (NADP-ME grass); c Panicum miliaceum (NAD-ME grass); and d $\mathrm{Meg}$ athyrsus maximus (PCK grass). $\mathrm{LEF}_{\mathrm{O}_{2}}$ (the gross oxygen evolution rate multiplied by four) represents the linear electron flux through both photosystems. ETR1 is the measure of electron flux through PSI calculated using experimentally derived $f_{\mathrm{I}}$. CEF represents the cyclic electron flux around PSI calculated by subtracting $\mathrm{LEF}_{\mathrm{O}_{2}}$ from ETR1. Measurements were taken under the temperature of $28{ }^{\circ} \mathrm{C}$ and high $p \mathrm{CO}_{2}$ condition $(4 \%)$. Values are mean \pm S.E. $(n=4$ leaf discs $)$

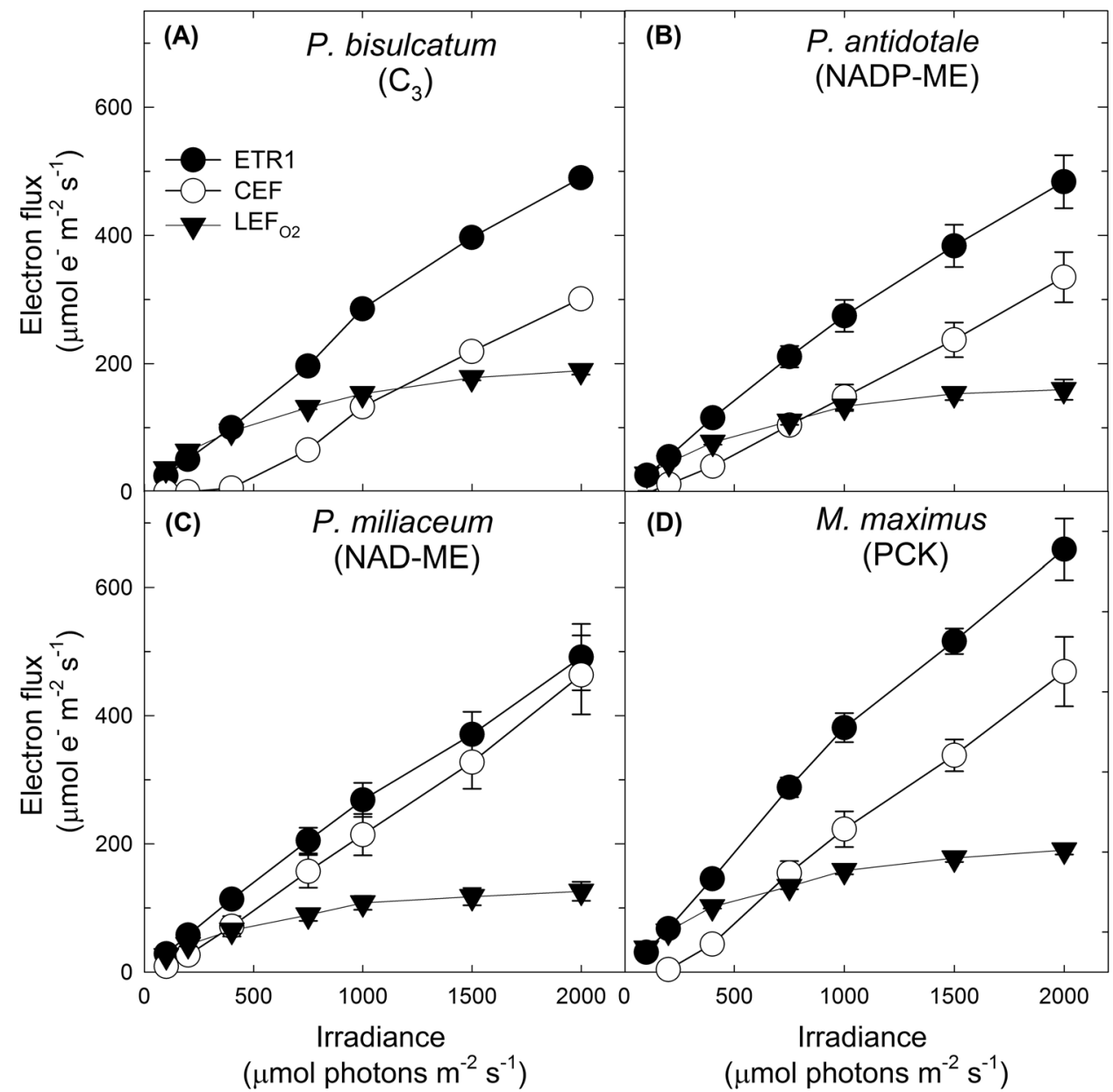

suggesting the physiological role in the activation of CEF around PSI.

\section{Comparison of $f_{\text {, }}$ across a wide range of species and in response to shade}

Higher value of $f_{\mathrm{I}}$ in $\mathrm{C}_{4}$ species compared to $\mathrm{C}_{3}$ species (Tables 1 and 2) validated the hypothesis that more excitation energy is distributed to PSI compared to PSII in $\mathrm{C}_{4}$ species. This was expected because leaves of $\mathrm{C}_{4}$ plants contain two types of photosynthetic cells, mesophyll and bundle sheath cells, which are quite distinctly organised, both structurally and functionally having varying PSI/PSII ratio depending on subtypes (Ghannoum et al. 2005; Romanowska and Albertsson 1994; Romanowska et al. 2008; Romanowska and Drożak 2006; Drozak and Romanowska 2006). For the representative species of gymnosperm, liverwort and fern, the higher values of $f_{\mathrm{II}}$ compared to $f_{\mathrm{I}}$ suggest the greater amount of PSII components relative to PSI in mesophyll chloroplasts. These shifted $f_{\text {I }}$ and $f_{\text {II }}$ values might be related to processes involving flavodiiron proteins (Flv) and other PSI protection mechanisms in these species. As such, they may utilise greater pseudo-cyclic pathways to balance energy requirements and inputs and alleviate photo-oxidative damage (Allahverdiyeva et al. 2015; Hanawa et al. 2017; Ilík et al. 2017; Noridomi et al. 2017; Shimakawa et al. 2017; Shirao et al. 2013). However, further experiments involving morphological and biochemical examinations of the leaf should be done to quantify functional PSI and PSII contents as well as the antenna size of each photosystem in these species.

Growth irradiance is also believed to affect the distribution of excitation energy by modulating the composition of light-harvesting antennas of PSI and PSII (Anderson 1986; Huner et al. 2003; Tanaka and Melis 1997). Growth under low light promotes large PSI and PSII antenna size, whereas growth under high light generates a small photosynthetic unit (Akoumianaki-Ioannidou et al. 2004; Huner et al. 2003; Leong and Anderson 1984). In $C_{3}$ plants, the value of $f_{\text {II }}$ was expected to be greater than that of $f_{\mathrm{I}}$ because PSII absorbs more light than PSI and this proportion increases with adaptation to shade based on the study of Evans (1986). But the result of this study showed that in the $\mathrm{C}_{3}$ model species spinach, almost $50 \%$ of the absorbed light was partitioned to PSII and the other 50\% to PSI (Table 1) which 


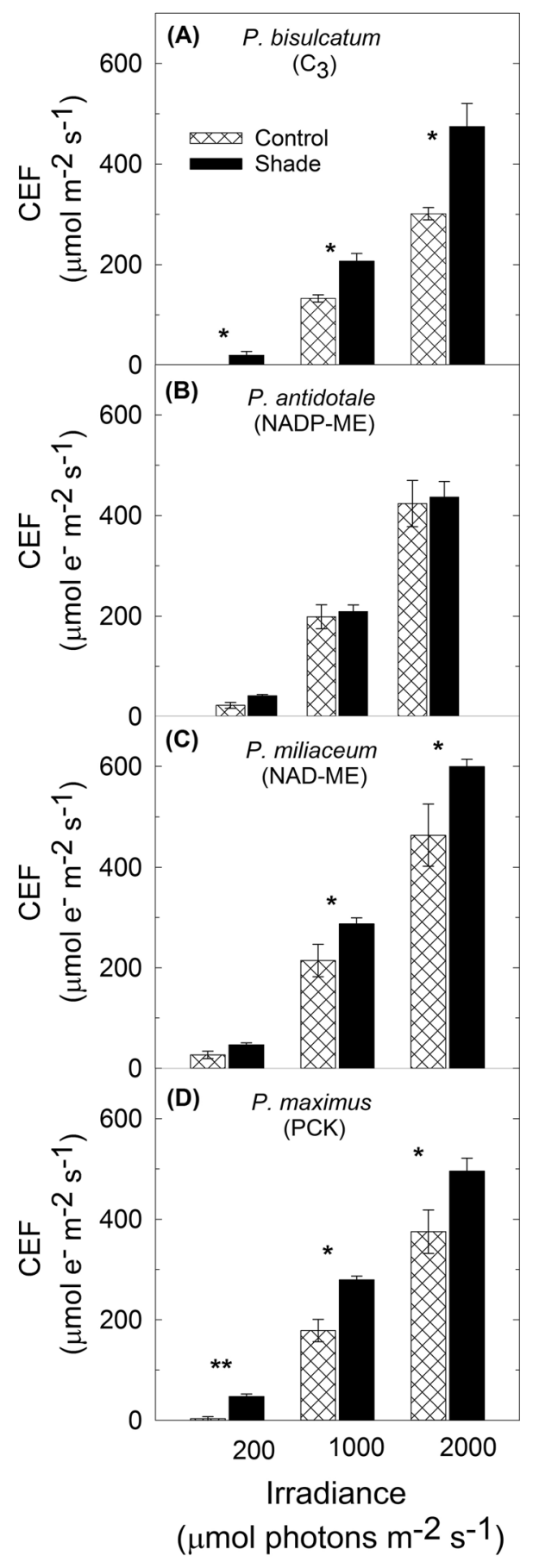

Fig. 3 Cyclic electron flux around PSI (CEF) in response to low, medium and saturating irradiance $(200,1000,2000 \mu \mathrm{mol}$ photons $\mathrm{m}^{-2} \mathrm{~s}^{-1}$ ) measured under the temperature of $28{ }^{\circ} \mathrm{C}$ and high $p \mathrm{CO}_{2}$ condition (4\%) in leaf discs of control and shade-grown a Panicum bisulcatum ( $\mathrm{C}_{3}$ grass); b Panicum antidotale (NADP-ME grass); c Panicum miliaceum (NAD-ME grass); and $\mathbf{d}$ Megathyrsus maximus (PCK grass). Each column represents the mean \pm S.E. of species ( $n=4$ leaf discs) at each light intensity. Statistical significance levels ( $t$ test) for the growth condition within each species and measurement light intensity are shown, and they are: ${ }^{*} p<0.05 ; * * p<0.01$; $* * * p<0.001$
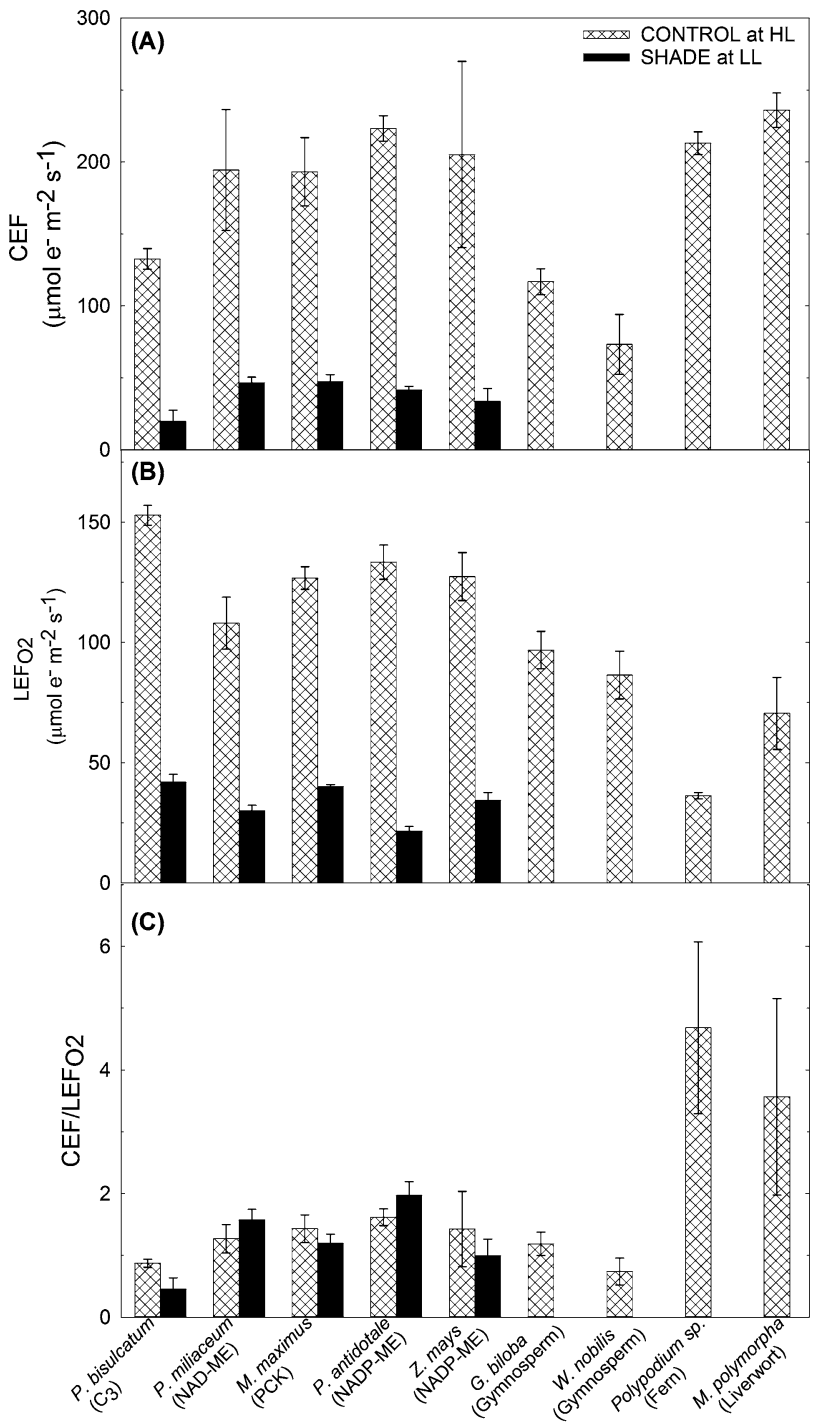

Fig. 4 a Cyclic electron flux through PSI (CEF); b linear electron flux through both photosystems $\left(\mathrm{LEF}_{\mathrm{O}_{2}}\right)$; and $\mathbf{c}$ the ratio of CEF to $\mathrm{LEF}_{\mathrm{O}_{2}}$ of control plants measured at $1000 \mu \mathrm{mol}$ photons $\mathrm{m}^{-2} \mathrm{~s}^{-1}$ (HL) and shade-grown plants measured at $200 \mu$ mol photons $\mathrm{m}^{-2} \mathrm{~s}^{-1}$ (LL). Measurements were taken under the temperature of $28{ }^{\circ} \mathrm{C}$ and high $p \mathrm{CO}_{2}$ condition (4\%) in leaf discs of Panicum bisulcatum $\left(\mathrm{C}_{3}\right.$ grass), Panicum antidotale (NADP-ME grass), Panicum miliaceum (NADME grass), Megathyrsus maximus (PCK grass), Zea mays (NADP$\mathrm{ME}$ ), Ginkgo biloba (Gymnosperm), Wollemi nobilis (Gymnosperm), Polypodium sp. (Fern) and Marchantia polymorpha (Liverwort). Each column represents the mean \pm S.E. of each species $(n=4$ leaf discs)

is consistent to the study of Fan et al. (2016) and Kou et al. (2013a), thus validating the reliability of this method. This partitioning is different in the leaf of control $\mathrm{C}_{3}$ grass $(P$. bisulcatum) examined where almost $60 \%$ of light was partitioned to PSII and this partitioning decreased when grown under shade. In the case of $\mathrm{C}_{4}$ plants, a large fraction of the absorbed light energy ( $60 \%)$ was partitioned to PSI in the leaf of control plants and slightly increased in shade-grown 
plants. Several studies showed that adaptation to shade can increase $f_{\text {II }}$ because of the lowering of the chlorophyll $a / b$ ratio which will increase the amount of chlorophyll associated with PSII relative to chlorophyll associated with PSI (Walters and Horton 1995; Hogewoning et al. 2012; Murakami et al. 2016, 2017; Chow et al. 1990). However, the results obtained here were different from their findings for both shade-grown $\mathrm{C}_{3}$ and $\mathrm{C}_{4}$ grasses. An increase in PSI content has previously been observed by Bailey et al. (2001), but this change occurred only under very low irradiance with light intensities below $100 \mu \mathrm{mol}$ photons $\mathrm{m}^{-2} \mathrm{~s}^{-1}$. The slight decrease in $f_{\mathrm{II}}$ values of shade-grown plants (Table 1) can also be attributed to the light consumption brought about by the accessory pigment content of the photosynthetic complexes which were altered during shade acclimation (Laisk et al. 2014).

\section{CEF at increasing irradiance}

The very low CEF rate observed at $\leq 300 \mu \mathrm{mol}$ photons $\mathrm{m}^{-2}$ $\mathrm{s}^{-1}$ (Figs. 2a-d, 3a-d and Tables 2 and S 2) is because Calvin cycle was able to use the majority of NADPH at low irradiance, leaving little spare reduced ferredoxin for poising $\mathrm{CEF}$. At maximum $\mathrm{LEF}_{\mathrm{O}_{2}}$, however, more reduced ferredoxin would be available for competition between $\mathrm{NADP}^{+}$reduction and poising of CEF (Kou et al. 2013a; Okegawa et al. 2008) and CEF was larger than $\mathrm{LEF}_{\mathrm{O}_{2}}$ (Fig. 2a-d, Table S 2). This can be attributed to spectral distribution of the actinic light used in this study which favoured CEF over LEF. The actinic light from the halogen lamp used induced $\mathrm{CEF}$ above $500 \mu$ mol photons $\mathrm{m}^{-2} \mathrm{~s}^{-1}$ in control $\mathrm{C}_{3}$ grass and above $300 \mu \mathrm{mol}$ photons $\mathrm{m}^{-2} \mathrm{~s}^{-1}$ in control $\mathrm{C}_{4}$ grasses. However, CEF was induced at lower irradiance $(\leq 200 \mu$ mol photons $\mathrm{m}^{-2} \mathrm{~s}^{-1}$ ) in shade-grown $\mathrm{C}_{3}$ and $\mathrm{C}_{4}$ grasses (Fig. $3 \mathrm{a}-\mathrm{d}$; Table $\mathrm{S} 2$ ), suggesting the formation of more reduced ferredoxin under low light and that the Calvin-Benson cycle started to get saturated with NADPH. This demonstrates the significant effect of the spectral distribution of actinic light on the CEF being investigated.

\section{Induction of CEF among different species $\left(C_{3}\right.$ and $C_{4}$ grasses, gymnosperms, ferns and liverwort) under high light}

Although no significant difference was observed between the CEF of control species measured at medium irradiance (Fig. 4c; Table S 2), CEF started to operate between 400 and $750 \mu$ mol photons $\mathrm{m}^{-2} \mathrm{~s}^{-1}$ in $\mathrm{C}_{3}$ grass and gymnosperm species while operation of CEF in other species started at much lower irradiance, suggesting the greater capacity for CEF in $\mathrm{C}_{4}$ and fern species (Table $\mathrm{S} 2$ ). Since it is widely known that CEF is crucial for a proper balance of NADPH and ATP in the thylakoid stroma of photosynthetic organisms (Golding and
Johnson 2003; Hatch 1987; Huang et al. 2012; Johnson 2011; Kramer and Evans 2011; Miyake 2010; Munekage et al. 2004; Rumeau et al. 2007; Shikanai 2007; Takabayashi et al. 2005; Takahashi et al. 2009), differences in the capacity for CEF can be due to differences in the energy requirement among species. In $\mathrm{C}_{4}$ plants, both $\mathrm{C}_{3}$ and $\mathrm{C}_{4}$ cycles are functional, thereby increasing the energetic cost of assimilating $\mathrm{CO}_{2}$ relative to that in $\mathrm{C}_{3}$ plants under varying irradiances.

Little is known about the energy requirements of ferns and liverworts and their capacities for CEF under varying irradiances. However, early onset of CEF under low irradiance in these species (Table S 2) suggests that it served as a mechanism to protect the photosynthetic apparatus from photodamage since $\mathrm{CEF}$ can generate a $\Delta \mathrm{pH}$ across the thylakoid membrane through increased electron transfer from PSI back to plastoquinone, thus activating NPQ under intense radiation (Carlquist and Schneider 2001; Watkins et al. 2007). Induction of CEF in gymnosperms at higher irradiance in comparison with other species (Table S 2) might be due to the ecophysiological traits of these species. Gymnosperms commonly grow in the mid- to high-latitude regions of the Northern Hemisphere where severe climatic conditions such as chilling temperatures are often experienced. As a result, they may be required to be more flexible than angiosperms to control photosynthesis according to surrounding environmental conditions (Shirao et al. 2013).

\section{Capacity for CEF among the $C_{4}$ subtypes}

Much rapid stimulation of $\mathrm{CEF}$ at low irradiance $\left(<400 \mu\right.$ mol photons $\left.\mathrm{m}^{-2} \mathrm{~s}^{-1}\right)$ in NADP-ME and NAD-ME species in comparison with PCK grass (Table S 2) can be due to differences in the energy requirements among subtypes. For example, in NADP-ME species, BSC require more ATP than MC. This assumption is supported by the findings that the BS chloroplasts of most NADP-ME species either completely lack or have less grana with little activity of PSII, which is indispensable for the production of ATP and NADPH in LEF (Chapman et al. 1980; Gutierrez et al. 1974; Hatch 1987; Kanai and Edwards 1999; Romanowska et al. 2008; Woo et al. 1970).

\section{Induction of CEF in shade-grown $C_{3}$ and $C_{4}$ species}

The intensity of light under which plants grow has a significant effect on CEF (Miyake et al. 2005). Highest increase in $\mathrm{CEF}$ rate under low and high irradiances was observed in the shade-grown $\mathrm{C}_{3}$ grass (Fig. 3a, Table $\mathrm{S} 2$ ), suggesting that $\mathrm{C}_{3}$ grass species is more efficient in maintaining a balance in the ATP/NADPH ratio under low-light conditions and can dissipate excess light energy harmlessly as heat under saturating light condition. This result also suggests that the induction of CEF in these shade-grown plants may serve as 
a photoprotective mechanism or to generate additional ATP switching from LEF to CEF as part of the acclimation strategy since it was shown that shade down-regulated $\mathrm{LEF}_{\mathrm{O}_{2}}$ in all species (Fig. 4b, Table $\mathrm{S} 2$ ). It has been shown that shadegrown Arabidopsis developed high PSI/PSII ratio in leaves which is preferentially involved in CEF to generate ATP, suggesting that this may be a way in which cells make the best use of the light available under such conditions (Joliot and Joliot 2006). However, it was shown by Miyake et al. (2005) that tobacco plants exposed to high light have greater capacity for both CEF and NPQ when compared with plants grown under low light. They have suggested that the main role of CEF in plants acclimated to high light is to dissipate excess light energy through NPQ when illuminated at high irradiance. Under low light, the rate of photosynthesis of high light acclimated plants tends to be limited by the rate of ATP production rather than by the rate of NADPH production. Therefore, it was assumed that CEF assisted with ATP synthesis under weaker light in control plants (Yamori et al. 2011). By contrast, for plants acclimated to low light, the rates of photosynthesis and photorespiration are expected to be low. Consequently, they should have reduced demand for CEF-dependent ATP regeneration. Thus, Yamori et al. (2011) speculated that, in plants exposed to low levels of light, the relatively low CEF activity corresponds to the ATP demand by primary metabolisms. Their results indicate that CEF primarily assists in maintaining a balance in the ATP/ NADPH ratio under sub-saturating light conditions but tends to mainly participate in photo-protection for PSI and PSII under saturating light conditions which can be true for the species of grasses used in our experiment.

No significant difference was observed in the capacity for CEF between control and shade-grown NADP-ME grass under low, medium and saturating irradiance (Fig. 3b, Tables 2 and $S$ 2), suggesting that CEF-dependent generation of $\Delta \mathrm{pH}$ mainly contributed to ATP synthesis under those levels of irradiance in control and shade-grown plants. This result somehow confirmed the findings of Sonawane et al. (2018) using several species of $\mathrm{C}_{4}$ grasses across subtypes. They showed that NAD-ME and to a lesser extent PCK species were generally outperformed by NADP-ME species. This response was underpinned by a more efficient $\mathrm{CCM}$ and quantum yield in NADP-ME.

\section{Conclusion}

In this study, we developed a reliable method to calculate the light partitioning between PSI and PSII $\left(f_{\mathrm{I}}\right.$ and $f_{\mathrm{II}}$, respectively) by combining P700 measurement using a DualPAM and LEF measurement using MIMS. We applied this method to estimate $f_{\mathrm{I}}$ for several plant species to determine whether $f_{\mathrm{I}}$ deviates from what is widely assumed $\left(f_{\mathrm{I}}=0.5\right)$ in the literature. $\mathrm{C}_{4}$ grasses had $f_{\mathrm{I}}$ of 0.6 which is higher than what is usually assumed. $\mathrm{C}_{3}$ grass had $f_{\mathrm{I}}$ of 0.4 which is lower compared to the model $\mathrm{C}_{3}$ species. Other species such as liverwort and fern had $f_{\mathrm{I}}$ of 0.5 , while gymnosperms had lower. However, it was also shown that these values can change depending on the growing conditions such as irradiance. Cyclic electron flow was negligible at very low irradiance; it was generally higher in $\mathrm{C}_{4}$ grasses and lower in gymnosperms. The values obtained here can be used to correctly quantify CEF and further used for photosynthesis modelling.

Acknowledgements This research was funded by the Australian Research Council Centre of Excellence for Translational Photosynthesis (CE140100015) awarded to OG and MRB. JVS gratefully acknowledges the award of a Higher Degree Research Scholarship funded through the Centre of Excellence for Translational Photosynthesis and Western Sydney University.

Author contributions All authors conceived the research plans; JVS performed the experiments under BMR and CWS supervision; JVS and OG wrote the article with contribution from other authors.

\section{Compliance with ethical standards}

Conflict of interest The authors declare that they have no conflict of interest.

Open Access This article is distributed under the terms of the Creative Commons Attribution 4.0 International License (http://creativeco mmons.org/licenses/by/4.0/), which permits unrestricted use, distribution, and reproduction in any medium, provided you give appropriate credit to the original author(s) and the source, provide a link to the Creative Commons license, and indicate if changes were made.

\section{References}

Akoumianaki-Ioannidou A, Georgakopoulos JH, Fasseas C, Argyroudi-Akoyunoglou JH (2004) Photoacclimation in Spathiphyllum. J Photochem Photobiol B 73(3):149-158

Allahverdiyeva Y, Isojärvi J, Zhang P, Aro E-M, Allahverdiyeva Y, Isojärvi J, Aro E-M et al (2015) Cyanobacterial oxygenic photosynthesis is protected by Flavodiiron proteins. Life 5(1):716-743

Allen JF (2003) Cyclic, pseudocyclic and noncyclic photophosphorylation: new links in the chain. Trends Plant Sci 8(1):15-19

Anderson JM (1986) Photoregulation of the composition, function, and structure of thylakoid membranes. Ann Rev Plant Physiol 37:93-136

Bailey S, Walters RG, Jansson S, Horton P (2001) Acclimation of Arabidopsis thaliana to the light environment: the existence of separate low light and high light responses. Planta 213(5):794-801

Beckmann K, Messinger J, Badger MR, Wydrzynski T, Hillier W (2009) On-line mass spectrometry: membrane inlet sampling. Photosynth Res 102(2):511-522

Burrows PA, Sazanov LA, Svab Z, Maliga P, Nixon PJ (1998) Identification of a functional respiratory complex in chloroplasts through analysis of tobacco mutants containing disrupted plastid $n d h$ genes. EMBO J 17(4):868-876 
Canvin DT, Berry JA, Badger MR, Fock H, Osmond CB (1980) Oxygen exchange in leaves in the light. Plant Physiol 66(2):302-307

Carlquist S, Schneider EL (2001) Vessels in ferns: structural, ecologi$\mathrm{cal}$, and evolutionary significance. Am J Bot 88(1):1-13

Chapman KSR, Berry JA, Hatch MD (1980) Photosynthetic metabolism in bundle sheath cells of the $\mathrm{C}_{4}$ species Zea mays: sources of ATP and NADPH and the contribution of photosystem II. Arch Biochem Biophys 202(2):330-341

Chow WS, Hope AB, Anderson JM (1989) Oxygen per flash from leaf disks quantifies photosystem II. BBA Bioenerg 973(1):105-108

Chow WS, Melis A, Anderson JM (1990) Adjustments of photosystem stoichiometry in chloroplasts improve the quantum efficiency of photosynthesis. PNAS 87(19):7502-7506

DalCorso G, Pesaresi P, Masiero S, Aseeva E, Schünemann D, Finazzi G, Leister D et al (2008) A complex containing PGRL1 and PGR5 is involved in the switch between linear and cyclic electron flow in Arabidopsis. Cell 132(2):273-285

Drozak A, Romanowska E (2006) Acclimation of mesophyll and bundle sheath chloroplasts of maize to different irradiances during growth. BBA Bioenerg 1757(11):1539-1546

Evans JR (1986) A quantitative analysis of light distribution between the two photosystems, considering variation in both the relative amounts of the chlorophyll-protein complexes and the spectral quality of light. Photobiochem Photobiophys 10:135-147

Fan DY, Fitzpatrick D, Oguchi R, Ma W, Kou J, Chow WS (2016) Obstacles in the quantification of the cyclic electron flux around photosystem $\mathrm{I}$ in leaves of $\mathrm{C}_{3}$ plants. Photosynth Res 129(3):239-251

Genty B, Briantais J-M, Baker NR (1989) The relationship between the quantum yield of photosynthetic electron transport and quenching of chlorophyll fluorescence. BBA Gen Subj 990:87-92

Ghannoum O, Evans JR, Chow WS, Andrews TJ, Conroy JP, von Caemmerer $\mathrm{S}$ (2005) Faster rubisco is the key to superior nitrogen-use efficiency in NADP-malic enzyme relative to NAD-malic enzyme $\mathrm{C}_{4}$ grasses. Plant Physiol 137(2):638-650

Godde D (1982) Evidence for a membrane bound NADH-plastoquinone-oxidoreductase in Chlamydomonas reinhardii CW-15. Arch Microbiol 131(3):197-202

Golding AJ, Johnson GN (2003) Down-regulation of linear and activation of cyclic electron transport during drought. Planta 218(1):107-114

Gutierrez M, Gracen VE, Edwards GE (1974) Biochemical and cytological relationships in $\mathrm{C}_{4}$ plants. Planta 119(4):279-300

Hanawa H, Ishizaki K, Nohira K, Takagi D, Shimakawa G, Sejima T, Miyake $C$ et al (2017) Land plants drive photorespiration as higher electron-sink: comparative study of post-illumination transient $\mathrm{O}_{2}$-uptake rates from liverworts to angiosperms through ferns and gymnosperms. Physiol Plant 161(1):138-149

Hatch MD (1987) C4 photosynthesis: a unique blend of modified biochemistry, anatomy and ultrastructure. BBA Rev Bioenerg 895(2):81-106

Hernández-Prieto MA, Foster C, Watson-Lazowski A, Ghannoum O, Chen M (2019) Comparative analysis of thylakoid protein complexes in the mesophyll and bundle sheath cells from $\mathrm{C} 3, \mathrm{C} 4$ and C3-C4 Paniceae grasses. Physiol Plant 166(1):134-147

Hogewoning SW, Wientjes E, Douwstra P, Trouwborst G, van Ieperen W, Croce R, Harbinson J (2012) Photosynthetic quantum yield dynamics: from photosystems to leaves. Plant Cell 24(5):1921-1935

Horton P, Ruban AV, Rees D, Pascal AA, Noctor G, Young AJ (1991) Control of the light-harvesting function of chloroplast membranes by aggregation of the LHCII chlorophyll-protein complex. FEBS Lett 292(1-2):1-4

Horváth EM, Peter SO, Joët T, Rumeau D, Cournac L, Horváth GV, Medgyesy P et al (2000) Targeted inactivation of the plastid $n d h B$ gene in tobacco results in an enhanced sensitivity of photosynthesis to moderate stomatal closure. Plant Physiol 123(4):1337-1350

Huang W, Yang SJ, Zhang SB, Zhang JL, Cao KF (2012) Cyclic electron flow plays an important role in photoprotection for the resurrection plant Paraboea rufescens under drought stress. Planta 235(4):819-828

Huner NPA, Öquist G, Melis A (2003) Photostasis in plants, green algae and cyanobacteria: the role of light-harvesting antenna complexes. In: Green BR (ed) Light-harvesting antennas in photosynthesis. Springer, Dordrecht

Ikezawa N, Ifuku K, Endo T, Sato F (2002) Inhibition of photosystem II of spinach by the respiration inhibitors piericidin A and thenoyltrifluoroacetone. Biosci Biotechnol Biochem 66(9):1925-1929

Ilík P, Pavlovič A, Kouřil R, Alboresi A, Morosinotto T, Allahverdiyeva Y, Shikanai T et al (2017) Alternative electron transport mediated by flavodiiron proteins is operational in organisms from cyanobacteria up to gymnosperms. New Phytol 214(3):967-972

Ivanov B, Asada K, Kramer DM, Edwards G (2005) Characterization of photosynthetic electron transport in bundle sheath cells of maize. I. Ascorbate effectively stimulates cyclic electron flow around PSI. Planta 220(4):572-581

Johnson GN (2011) Reprint of: physiology of PSI cyclic electron transport in higher plants. BBA Bioenerg 1807(8):906-911

Joliot P, Joliot A (2006) Cyclic electron flow in $\mathrm{C}_{3}$ plants. BBA Bioenerg 1757(5-6):362-368

Kanai R, Edwards GE (1999) The biochemistry of $C_{4}$ photosynthesis. In: Sage RF, Monson RK (eds) C4 plant biology. Academic Press, San Diego

Klughammer C, Schreiber U (1994) An improved method, using saturating light-pulses, for the determination of photosystem I quantum yield via P700+-absorbance changes at $830 \mathrm{~nm}$. Planta 192(2):261-268

Klughammer C, Schreiber U (2008) Saturation pulse method for assessment of energy conversion in PS I. PAM Appl Notes 1:11-14

Kono M, Noguchi K, Terashima I (2014) Roles of the cyclic electron flow around PSI (CEF-PSI) and $\mathrm{O}_{2}$-dependent alternative pathways in regulation of the photosynthetic electron flow in shortterm fluctuating light in Arabidopsis thaliana. Plant Cell Physiol 55(5):990-1004

Kou J, Takahashi S, Oguchi R, Badger MR, Chow WS (2013a) Quantification of cyclic electron flow in spinach leaf discs. In: Kuang $\mathrm{T}$ (ed) Photosynthesis research for food, fuel and the future. Advanced topics in science and technology in China. Springer, Berlin

Kou J, Takahashi S, Oguchi R, Fan D-Y, Badger MR, Chow WS (2013b) Estimation of the steady-state cyclic electron flux around PSI in spinach leaf discs in white light, $\mathrm{CO}_{2}$-enriched air and other varied conditions. Funct Plant Biol 40(10):1018-1028

Kou J, Takahashi S, Fan D-Y, Badger MR, Chow WS (2015) Partially dissecting the steady-state electron fluxes in Photosystem I in wild-type and pgr5 and $n d h$ mutants of Arabidopsis. Front Plant Sci 6:758

Kramer DM, Evans JR (2011) The importance of energy balance in improving photosynthetic productivity. Plant Physiol 155(1):70-78

Laisk A, Loreto F (1996) Determining photosynthetic parameters from leaf $\mathrm{CO}_{2}$ exchange and chlorophyll fluorescence. Plant Physiol 110(3):903-912

Laisk A, Oja V, Eichelmann H, Dall'Osto L (2014) Action spectra of photosystems II and I and quantum yield of photosynthesis in leaves in state 1. BBA Bioenerg 1837(2):315-325

Leong TY, Anderson JM (1984) Adaptation of the thylakoid membranes of pea chloroplasts to light intensities. I. Study on the distribution of chlorophyll-protein complexes. Photosynth Res $5(2): 105-115$ 
Loreto F, Tsonev T, Centritto M (2009) The impact of blue light on leaf mesophyll conductance. J Exp Bot 60(8):2283-2290

Maxwell K, Badger MR, Osmond CB (1998) A comparison of $\mathrm{CO}_{2}$ and $\mathrm{O}_{2}$ exchange patterns and the relationship with chlorophyll fluorescence during photosynthesis in $\mathrm{C}_{3}$ and CAM plants. Aust J Plant Physiol 27(6):45-52

Miyake C (2010) Alternative electron flows (water-water cycle and cyclic electron flow around PSI) in photosynthesis: molecular mechanisms and physiological functions. Plant Cell Physiol 51(12):1951-1963

Miyake C, Yokota A (2000) Determination of the rate of photoreduction of $\mathrm{O}_{2}$ in the water-water cycle in watermelon leaves and enhancement of the rate by limitation of photosynthesis. Plant Cell Physiol 41(3):335-343

Miyake C, Shinzaki Y, Miyata M, Tomizawa K-I (2004) Enhancement of cyclic electron flow around PSI at high light and its contribution to the induction of non-photochemical quenching of chl fluorescence in intact leaves of tobacco plants. Plant Cell Physiol 45(10): 1426-1433

Miyake C, Miyata M, Shinzaki Y, Tomizawa KI (2005) $\mathrm{CO}_{2}$ response of cyclic electron flow around PSI (CEF-PSI) in tobacco leavesrelative electron fluxes through PSI and PSII determine the magnitude of non-photochemical quenching (NPQ) of chl fluorescence. Plant Cell Physiol 46(4):629-637

Munekage Y, Hojo M, Meurer J, Endo T, Tasaka M, Shikanai T (2002) PGR5 is involved in cyclic electron flow around photosystem I and is essential for photoprotection in Arabidopsis. Cell 110(3):361-371

Munekage Y, Hashimoto M, Miyake C, Tomizawa K, Endo T, Tasaka M, Shikanai T (2004) Cyclic electron flow around photosystem I is essential for photosynthesis. Nature 429(6991):579-582

Murakami K, Matsuda R, Fujiwara K (2016) Interaction between the spectral photon flux density distributions of light during growth and for measurements in net photosynthetic rates of cucumber leaves. Physiol Plant 158(2):213-224

Murakami K, Matsuda R, Fujiwara K (2017) Quantification of excitation energy distribution between photosystems based on a mechanistic model of photosynthetic electron transport. Plant Cell Environ 41:148-159

Noridomi M, Nakamura S, Tsuyama M, Futamura N, Vladkova R (2017) Opposite domination of cyclic and pseudocyclic electron flows in short-illuminated dark-adapted leaves of angiosperms and gymnosperms. Photosynth Res 134(2):149-164

Okegawa Y, Kagawa Y, Kobayashi Y, Shikanai T (2008) Characterization of factors affecting the activity of photosystem I cyclic electron transport in chloroplasts. Plant Cell Physiol 49(5):825-834

Romanowska E, Albertsson PA (1994) Isolation and characterization of the cytochrome $b f$ complex from whole thylakoids, grana, and stroma lamellae vesicles from spinach chloroplasts. Plant Cell Physiol 35(4):557-568

Romanowska E, Drożak A (2006) Comparative analysis of biochemical properties of mesophyll and bundle sheath chloroplasts from various subtypes of $\mathrm{C}_{4}$ plants grown at moderate irradiance. Acta Biochim Pol 53(4):709-719

Romanowska E, Kargul J, Powikrowska M, Finazzi G, Nield J, Drozak A, Pokorska B (2008) Structural organization of photosynthetic apparatus in agranal chloroplasts of maize. J Biol Chem 283(38):26037-26046

Rumeau D, Peltier G, Cournac L (2007) Chlororespiration and cyclic electron flow around PSI during photosynthesis and plant stress response. Plant Cell Environ 30(9):1041-1051

Shikanai T (2007) Cyclic electron transport around photosystem I: genetic approaches. Annu Rev Plant Biol 58:199-217

Shikanai T (2014) Central role of cyclic electron transport around photosystem I in the regulation of photosynthesis. Curr Opin Biotechnol 26:25-30
Shikanai T (2016) Chloroplast NDH: a different enzyme with a structure similar to that of respiratory NADH dehydrogenase. BBA Bioenerg 1857(7):1015-1022

Shikanai T, Endo T, Hashimoto T, Yamada Y, Asada K, Yokota A (1998) Directed disruption of the tobacco $n d h B$ gene impairs cyclic electron flow around photosystem I. PNAS 95(16):9705-9709

Shimakawa G, Ishizaki K, Tsukamoto S, Tanaka M, Sejima T, Miyake C (2017) The liverwort, Marchantia, drives alternative electron flow using a flavodiiron protein to protect PSI. Plant Physiol 173(3):1636-1647

Shirao M, Kuroki S, Kaneko K, Kinjo Y, Tsuyama M, Förster B, Badger MR et al (2013) Gymnosperms have increased capacity for electron leakage to oxygen (Mehler and PTOX reactions) in photosynthesis compared with angiosperms. Plant Cell Physiol 54(7):1152-1163

Siebke K, von Caemmerer S, Badger M, Furbank RT (1997) Expressing an $\mathrm{RbcS}$ antisense gene in transgenic Flaveria bidentis leads to an increased quantum requirement for $\mathrm{CO}_{2}$ fixed in photosystems I and II. Plant Physiol 115(3):1163-1174

Sonawane BV, Sharwood RE, Whitney S, Ghannoum O (2018) Shade compromises the photosynthetic efficiency of NADP-ME less than that of PEP-CK and NAD-ME C4 grasses. J Exp Bot 69(12):3053-3068

Takabayashi A, Kishine M, Asada K, Endo T, Sato F (2005) Differential use of two cyclic electron flows around photosystem I for driving $\mathrm{CO}_{2}$-concentration mechanism in $\mathrm{C}_{4}$ photosynthesis. PNAS 102(46): 16898-16903

Takahashi S, Badger MR (2011) Photoprotection in plants: a new light on photosystem II damage. Trends Plant Sci 16(1):53-60

Takahashi S, Milward SE, Fan D-Y, Chow WS, Badger MR (2009) How does cyclic electron flow alleviate photoinhibition in Arabidopsis? Plant Physiol 149(3):1560-1567

Takahashi H, Clowez S, Wollman FA, Vallon O, Rappaport F (2013) Cyclic electron flow is redox-controlled but independent of state transition. Nat Commun 4:1954

Tanaka A, Melis A (1997) Irradiance-dependent changes in the size and composition of the chlorophyll a-b light-harvesting complex in the green alga Dunaliella salina. Plant Cell Physiol 38(1):17-24

Walters RG, Horton P (1995) Acclimation of Arabidopsis thaliana to the light environment: regulation of chloroplast composition. Planta 197:475-481

Watkins JE, Mack MC, Sinclair TR, Mulkey SS (2007) Ecological and evolutionary consequences of desiccation tolerance in tropical fern gametophytes. New Phytol 176(3):708-717

Woo KC, Anderson JM, Boardman NK, Downton WJ, Osmond CB, Thorne SW (1970) Deficient photosystem II in agranal bundle sheath chloroplasts of $\mathrm{C}_{4}$ plants. PNAS 67(1):18-25

Yamori W, Shikanai T (2016) Physiological functions of cyclic electron transport around photosystem I in sustaining photosynthesis and plant growth. Annu Rev Plant Biol 67:81-106

Yamori W, Sakata N, Suzuki Y, Shikanai T, Makino A (2011) Cyclic electron flow around photosystem I via chloroplast NAD $(\mathrm{P}) \mathrm{H}$ dehydrogenase (NDH) complex performs a significant physiological role during photosynthesis and plant growth at low temperature in rice. Plant J 68(6):966-976

Zhang M-M, Fan D-Y, Sun G-Y, Chow WS (2018) Optimising the linear electron transport rate measured by chlorophyll a fluorescence to empirically match the gross rate of oxygen evolution in white light: towards improved estimation of the cyclic electron flux around photosystem I in leaves. Funct Plant Biol 45(11):1138-1148

Publisher's Note Springer Nature remains neutral with regard to jurisdictional claims in published maps and institutional affiliations. 